\title{
Digital news resources: An autoethnographic study of news encounters
}

\author{
Sally Jo Cunningham, David M. Nichols, Annika Hinze, Judy Bowen \\ Dept. of Computer Science, University of Waikato, Private Bag 3105, Hamilton New Zealand \\ sallyjo, daven, hinze, jbowen @waikato.ac.nz
}

\begin{abstract}
We analyze a set of 35 autoethnographies of news encounters, created by students in New Zealand. These comprise rich descriptions of the news sources, modalities, topics of interest, and news 'routines' by which the students keep in touch with friends and maintain awareness of personal, local, national, and international events. We explore the implications for these insights into news behavior for further research to support digital news systems.
\end{abstract}

Keywords: news behavior, qualitative research, digital news resources, news encounter, personal digital library

\section{$1 \quad$ Introduction}

The news landscape has changed considerably over the past decade with social media platforms creating new dissemination channels for information. The inherently social nature of systems such as Facebook has encouraged both recommendations of conventional news items and widened the conception of news itself. The resulting ecosystem of consumption, creation and sharing presents a complex landscape of news far removed from just broadcast television news and print newspapers. Our understanding of these news interactions informs both the creation of access tools for current users (such as recommender systems and visualizations) and the design of news archive collections for future users. In this present paper we add to this understanding of news behavior by exploring the news practices of $35 \mathrm{New}$ Zealand tertiary students in both the digital and physical context. This research is qualitative; as such it inevitably highlights areas for further research into news behavior and appropriate interface and interaction design for more effective news provision systems.

\section{Related work}

The growth of online content, and social media in particular, has been widely reported as changing the news environment for users. Nielsen and Schrøder report that there is limited understanding of how important social media is as a source of news [11]. Recent studies suggest that, despite the growth of social media, trusted legacy brands and platforms remain important news channels [11] [15]. Social media has created a space

This is the authors' version.

The final publication is available at Springer via

http://dx.doi.org/10.1007/978-3-319-24592-8_7

Cite as:

Cunningham, S.J., Nichols, D.M., Hinze, A. and Bowen, J. (2015) Digital news resources: An autoethnographic study of news encounters, Proceedings of the 19th International Conference on Theory and Practice of Digital Libraries (TPDL 2015). Springer. 84-96. 
where "consumers collaboratively create and curate news stories" rather than receiving news from a limited number of 'authoritative' sources [12]. Hermida et al. report that these social channels are valued by users for the alternative filtering they provide but that social media use by "traditional" news sources (such as newspapers) is an important source of information [6]. Meijer and Kormelink reflect the potential richness of social media-enhanced news interactions in the 16 types of news activity reported by their interviewees: reading, watching, viewing, listening, checking, snacking, monitoring, scanning, searching, clicking, linking, sharing, liking, recommending, commenting and voting [1].

These micro-activities are complemented by higher-level classifications of behavior. Marshall categorized study participants using a New York Times news reading application into three groups: "Reading primarily for relaxation and as a diversion; Reading as a newshound, following the narrative of specific breaking stories or particular recommendations; Reading broadly to stay informed or to keep up with events of the day" [10]. Van Damme et al. categorize mobile news consumers as: omnivores (actively engaged using multiple channels), traditionals (intensive but loyal to established sources such as TV) and serendips (less of a news routine but digital when engaged) [15].

Characterizations of news consumers often use the intent of the user, whereas [16] note that incidental news exposure is common and, for digitally-connected citizens, increasingly difficult to avoid. Although sharing content is an important aspect of social media, [7] claim that it serves a personal as well a social function. Shared content persists in the platform as an archive that can be searched at a later date. Similarly, [10] notes that "a person's daily encounters with the news should become a fundamental part of ... a personal digital library." The diverse distributed cross-platform multimedia nature of users' news interactions suggests there are considerable technical and legal challenges to achieving that goal.

Although much has been written about social media, there is still uncertainty about the interaction between traditional news channels and social media [11]. [12] claim that "no studies so far have attempted to explore or explain the mechanism of news consumption processes in the context of socially connected interactive participants". However, in the light of studies such as [8] this claim may reflect a literature gap between the journalism and user interaction communities.

Location is an important feature of news; both the location of the consumer and the places referred to in news reports. Systems such as NewsStand [14] and NewsViews [4] attempt to extract geographical references from news reports to enable map-based interactions such as queries and visualizations. [8] found that personal news recommendations are more effective, possibly because social media users have an implicit model of their friends' preferences which pre-filters suggestions.

In summary, timeliness and location are key elements of news-based information systems. Users have adapted the diverse tools of social media for sharing and recommending news items. Social recommendations are effective as they leverage existing models of users' preferences and are often innately timely. Studies of news behavior that predate the growth of social media (e.g., [3]) are of limited applicability and there may be a lack of interaction between journalism studies and those in the computing literature. 


\section{$3 \quad$ Methodology}

Our study is based on a set of autoethnographies gathered from undergraduate students in New Zealand. In this section we describe the context in which the autoethnographies were created, our analysis method, and the limitations of this study.

\subsection{Data collection}

The data collection for this study was performed using personal ethnography (incorporating the use of diaries, self-observation and self-interviews), gathered in a semesterlong project in a third year university course on Human-Computer Interaction. The students were given the (deliberately broad and ambiguous) brief of designing and prototyping software to 'assist a person in accessing news'.

The first task for the students was to gather data on how people currently locate, manage, share or encounter news. To that end, they examined their own news-related behavior by completing a personal diary during the course of their everyday lives over a period of three days. For each encounter with a news item, the participants recorded the date and time, the number of news items they were exposed to during the encounter, the source, type (international, national, local or personal), the topic, how they encountered it and how believable it was (on a linear scale). The students then summarized and reflected on their diary entries as a post-diary 'debriefing'.

Next, the students reflected on how they managed their exposure to news items by creating autoethnographies [2] that identified the strategies, applications and resources they used and then investigated what types of media they were using, topics they were accessing and the activities they performed to actively locate news. They also observed any unexpected or chance encounters with news sources. Students were encouraged to reflect on their actual practices identified in the self-observation.

\subsection{Data analysis}

The diary study summaries and autoethnographies for 35 students were retained for analysis, out of an enrolment of 103. As is typical of New Zealand IT students, these selected participants are predominantly young (under 30 ). Though the majority of students in the course were male $(84 \mathrm{M}, 19 \mathrm{~F})$, we selected a higher proportion of the female students' work for analysis so that the female news experience would be better

Table 1. Student demographic details.

\begin{tabular}{l|l||l|l} 
Gender & Count $(\%)$ & Age at time of study & Count (\%) \\
\hline Male & $22(63 \%)$ & $<30$ years & $29(83 \%)$ \\
\hline Female & $13(37 \%)$ & $30-46$ years & $6(17 \%)$
\end{tabular}
represented. The course also included a significant number of international students (33 of 103); accordingly, we also limited our selection to students who were New Zealand citizens or permanent residents, as the experiences of international students could be expected to both differ greatly by their country of origin. Table 1 presents the demographic details for the 35 students whose work is analyzed in this study. These students were assigned a unique label (i.e., P1, P2, .. P35), and are referred to by that label in this paper. 
The diaries were retained by the students and so cannot be analyzed directly; instead, we view the recorded behavior through the diary study summaries and reflections. The entirety of the self-observation was available for analysis. These summaries and autoethnographies for the 35 students total over 200 printed pages; they were analyzed qualitatively using grounded theory methods [5], an iterative, inductive methodology that allows the participants' experiences, viewpoints, and conceptions to emerge naturally. Initial coding largely followed the categories included in the diary study summaries (Section 4), and further concepts emerged as these encounters were set in context by the autoethnographies (Section 5).

\subsection{Limitations of study}

Participating in a study is known to have the potential to alter behavior. The students themselves recognized that undertaking the assignment introduced changes to their news behavior ("I was more aware entirely of the news around me... sub-consciously listening out for news to include" [P22]; "I found myself not wanting to look at the news online as much since I would have to record it down.” [P31]). The assignment brief acknowledges these issues; in mitigation, the diaries included the option to indicate news events that occurred but were not noted, and the students were encouraged to explore deviations from their usual news behavior in the autoethnographies.

We recognize that the students likely felt a greater sense of commitment to completing the diaries and creating the autoethnographies than is usual with study participants, given that these activities were assessed. Participation in this present study, however, was not required; a student could opt out of inclusion by emailing a third party to indicate this desire. The assessors for the course were not informed of these decisions until after the semester's grades were finalized.

Given that this is an opportunistic study, we cannot claim to capture 'typical' behavior in searching / browsing / encountering news. As is characteristic of this style of study design, we instead build a rich picture of the news-related information behavior for these students, from their own perspective [13]. We demonstrate in Section 6 how this rich picture can suggest directions to explore both in developing software support for these behaviors and in further news information behavior studies.

\section{$4 \quad$ Results}

In this section we summarize the news sources consulted by the students, the news topics of interest to them, the characteristics of their common news behaviors ('routines'), and online and physical platforms that they use to access their news.

\subsection{News sources}

The students encountered news from a wide variety of sources (Figure 1), with an average of 4.4 significant news sources per student (Table 2). Only three students relied on a single news source; it was acknowledged in the other 32 autoethnographies 
that multiple sources were necessary for topic coverage and convenience of access

Table 2. Number of significant news sources per student.

\begin{tabular}{l|l|l|l|l|l|l|l|l} 
No. of sources & 1 & 2 & 3 & 4 & 5 & 6 & 7 & 8 \\
\hline No. of students & 3 & 2 & 10 & 13 & 4 & 1 & 1 & 1
\end{tabular}

("The 3 main ways that I access news [Facebook, email, mobile news app] all have good and bad at-

tributes and that's probably the reason why I don't just use one." [P17]

Facebook is by far the most heavily relied upon news source both in $S o$ cial Media and overall (Figure 1a). Its use goes well beyond providing personal news from family and friends; it is also a source for 'breaking' news of all topics. Twitter can be a 'Facebook lite' for news ("Twitter is a more short form of Facebook where I look at various tweets posted from friends, random users and any company or news agency to find out the latest news." [P1]). The blogs, vlogs, and forums were often focused on a topic of interest to the student, where use of Reddit and Tumblr was described as being more exploratory or serendipitous ("I never visit [Reddit] intending to encounter news but sometimes find myself reading or watching news after clicking on a link that

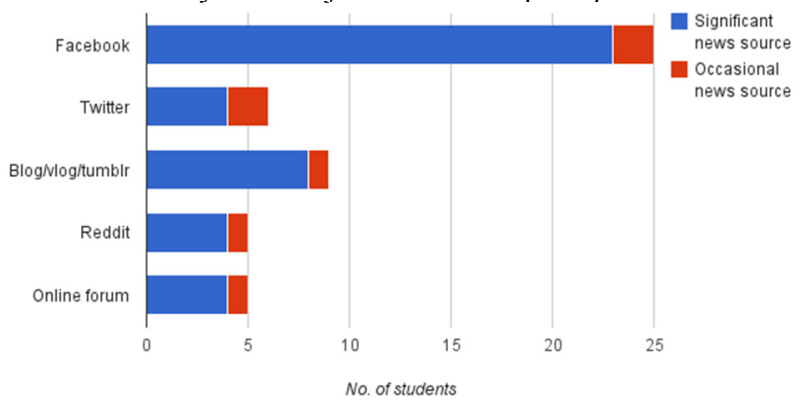

Fig. 1a. Social news sources

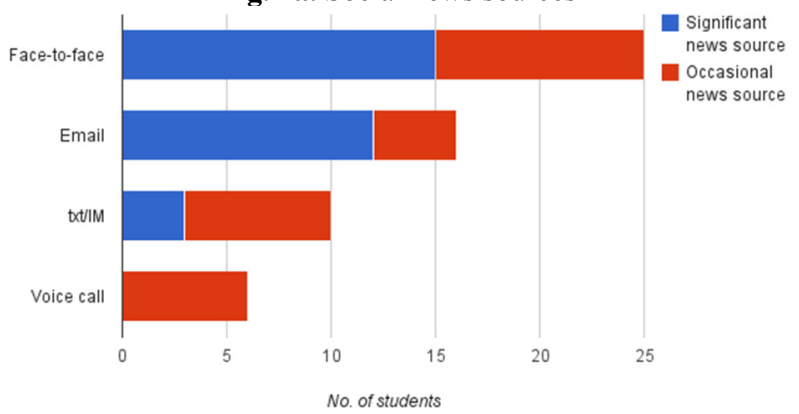

Fig. 1b. Inter-personal news sources

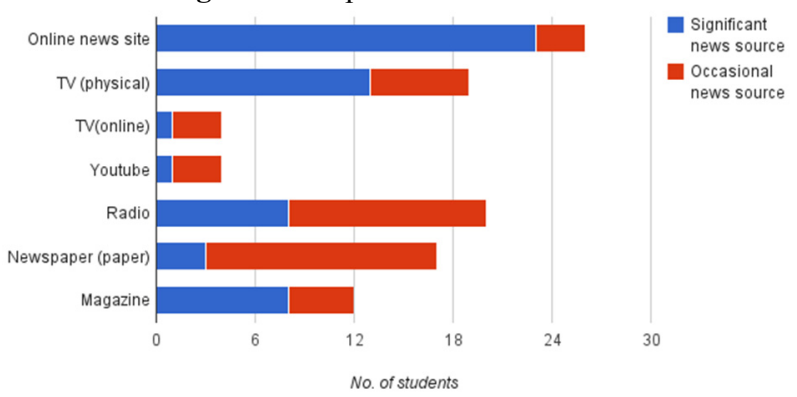

Fig. 1c. 'Official' news sources

Fig. 1. News sources used by students grabbed my attention..." [P19]).

Interpersonal news sources (Figure 1b) include face-to-face conversations (both with individuals and groups), SMS or IM messages, voice calls (via mobiles or VOIP), and email. The latter source most frequently elicits contact by a commercial organization or from an interest-based mailing list, and more rarely messages from friends or relatives. 
'Official' news sources such as television or radio broadcast news and newspapers are encountered in both digital and physical formats (Figure 1c). The online news sites consulted were primarily websites for the major New Zealand newspapers and the local news aggregator stuff.co.nz. These provide primarily text and still images. The physical (paper) newspapers and magazines were New Zealand focused and were either free (local weekly free papers, the university's student-run weekly magazine) or were freely accessible (at work breakrooms, parents' houses). Only one student reported purchasing a magazine subscription, and three reported occasionally purchasing a single issue of a magazine or newspaper if a story attracted their interest.

\subsection{News topics}

Figure 2 presents an overview of the news topics that students reported to be of signif-

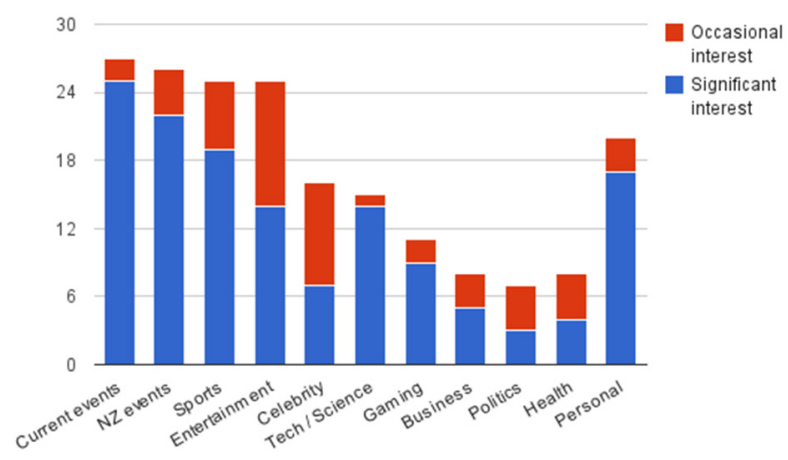
icant interest (i.e., they frequently sought out information on these topics) and of occasional interest (i.e., they infrequently sought out or encountered information of interest). Each student held a significant interest in at least two topics (Table 3 ), with an average of five topics per individual.

Fig 2. News topics of significant and occasional interest

Table 3. Number of topics that students held a significant interest in following.

\begin{tabular}{l|l|l|l|l|l|l|l} 
No. of topics of significant interest & 2 & 3 & 4 & 5 & 6 & 7 & 8 \\
\hline No. of students & 6 & 8 & 9 & 6 & 4 & 0 & 2
\end{tabular}

Current events is a broad category encompassing a range of categories typical of those covered by newspapers (e.g. wars, natural disasters, elections, etc.); NZ current events have a specifically New Zealand focus. Sports includes international, national, and local sporting news. Entertainment news covers the gamut of TV shows, music, movies, and other performances (but excluding games and sports), while Celebrity news is focused on a particular well-known person (including New Zealand and international celebrities). It is not surprising that students enrolled in an upper level Computer Science course would have strong interests in Technology and Science (primarily 'popular science' events and new hardware and software releases) and in Gaming. While Business included limited interests in conventional topics in that category (finance, banking, commercial trends), students' primary concerns were with topics that directly impacted them - particularly notifications of upcoming sales.

We note that significant international or local events influence an individual's news interests. As the autoethnographies were performed during the 2012 Olympics, students 
reported a higher than usual exposure to sports news, sparking in some an interest specifically in Olympics-related news but not in sports news in general (P25: "Without these events [the Olympic games] happening, there is very little likelihood that sports would feature in any of my diary entries."). Similarly, three students pointed out that they normally have little interest in politics, but "when election time comes up I make sure to check out the people I can vote for" [P23]. Further, an individual story in an uninteresting topic can capture interest if the student sees a personal link: “... I just get onto the NZ Herald web site and I see ... "Top lawyer guilty of misconduct". I do not like to read about politics because I find it boring, but I read about this because ... my sister is a lawyer ...". [P9]

\subsection{News routines}

The overwhelming majority - 31 of the 35 participants - reported having a news 'routine'. Some routines were simple: P14, for example, had arranged for a set of news feeds and email newsletters so that "The most common way that I encountered news was having it delivered to me." Other participants had developed more elaborate routines that spanned their entire day: "...I view news is usually first thing in the morning, check facebook see if any new news has appeared. Follow by checking to see the results from sports teams during the night. During the day I randomly check facebook and occasionally see new items in trending articles. At night I check stuff to see if anything interesting has occurred." [P5]).

The news activities in a particular routine could vary by:

Time of day: Generally the morning and / or the evening are important points in news routines,. News consumption can be helpful in waking up (on TV in the morning: “...it is a ritual I do when I wake up in the morning if I have a lot of time I'll watch it while eating breakfast, otherwise ill [sic] have it going in the background while I get ready." [P22]) and in relaxing after a day of study and work ([P20] reports "taking a good half hour to read through the news that has occurred over the course of the day while I wind down with a beer."). These news sessions tended to be longer and to involve active searching / browsing for news on the part of the participant. During the day, participants reported frequent news 'snacks' [1] to fill in time and avert boredom; these tended to be shorter (e.g., to fit in with work breaks or periods before a lecture started) and to involve checking newsfeeds.

Day of the week: Those students who reported having routines typically differentiated between routines for days involving scheduled work or study, and their free days. A free day might involve fewer news encounters (“...my Mondays this semester are ... my lazy day at home. Because of this the amount of news I generally encounter on a Monday is typically low." [P23]). However, if news encounters are motivated by relaxation or socialization, the number of encounters may increase (for face-to-face encounters, "on Saturday, the number of items each encounter yielded was greater. this could be related to the fact that on the weekends, my flatmates are all home, which allows us to have group conversation..." [P20]). A free day may also bring the student into contact with an additional source; for example, visiting the family home and finding "newspapers piled high in my parents' house" [P35]). 
Availability of the source: Consumption of several news sources were tied to their availability. While none of the students subscribed to a print newspaper, 17 cited it as a significant (3) or occasional (14) news source; these students regularly read the newspapers provided at work during a break, looked out for the university's student-published weekly on its distribution day ("If I do read a magazine it is usually the nexus [student paper] and it's only once a week usually Tuesday afternoon during one of my lectures" [P5]), or watch TV news broadcasts only on visits to their parents ("As we don't have a TV at our flat this is just when I'm home at the weekend." [P26]). Radio news was most commonly serendipitously encountered while in a car, typically driving to/from university or work. Only one student incorporated radio news into daily routine, with a radio in his bedroom.

\subsection{News platforms}

We identified three 'platforms' through which the students encountered news items: a standalone computer (desktop or laptop), a mobile device (tablet or handheld), and

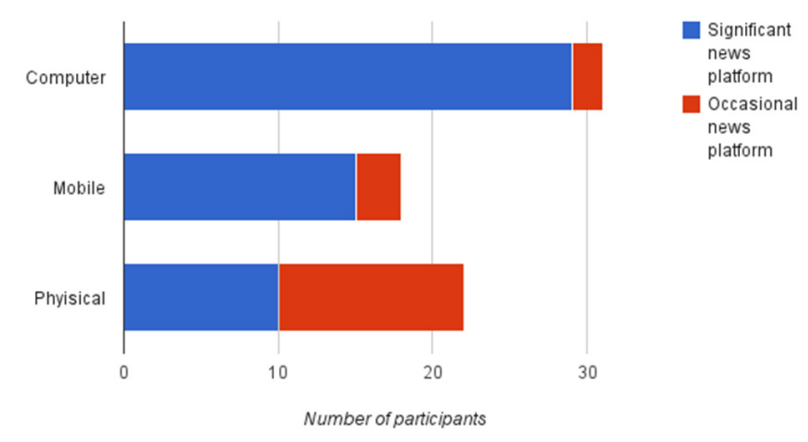

Fig. 3. Platforms for news encounters physical media (physical televisions, radio, newspapers, and magazines); see Figure 3. Three of the participants did not differentiate between computer and mobile use, simply stating that they preferred to access news 'online'. Of the remaining 32 participants, 30 used computers as a significant news access platform, and 14 of those also described their mobile as a significant access platform. Only one participant described significant use of a mobile but not of a computer as well.

Physical news sources continue to see use, with approximately $60 \%$ of the participants identifying them as significant or occasional sources for news. No student reported physical sources as their sole significant access platform.

Online access to news sources has obvious advantages: “....as long as there is an internet connection, they are easy and convenient to access, since I don't have to leave my bedroom to use them." [P17] Indeed, as students spend more time online, their access to physical or face-to-face news sources declines ("I spend approximately $6-10$ hours daily in front of my computer ... making the internet my only real source of information or news in any form." [P19]). 


\section{Discussion}

The students' conception of what constitutes news goes beyond topics covered by traditional news media ("...the topics I find personally newsworthy are not necessarily the more traditional ideas of what news is defined to be." [P25]). Their news has a greater focus on the personal - activities of friends and family - and events or activities that impact them directly (e.g., grocery store sales, updates to their favorite game). News interests are more narrowly focused than the broad categories of traditional news media (e.g., specific genres of music, movies, and television). Further, broadcast media can be difficult or impossible to skim/scan to filter out irrelevant or 'boring' news. P8 points out that with TV news shows, even those viewable online, "It is hard to know if the news on TV will have anything I'm interested in. They don't describe every item of news that they will cover. ... The news on TV is often only the important news at the start and less important news near the end. ... This means I have to wait till nearly the end of the news to see something I'm interested in." The students' heavy use of nontraditional news sources (e.g., Facebook, blogs, forums) partly stems from this desire to create a more personalized news information feed than is possible with conventional broadcast news.

The desired degree of direct control over this feed varies. Participants P14 and P31 occupy opposite ends of this spectrum: P14 prefers news that requires little filtering ("I am someone who is very lazy in seeking out news. I like to utilize news sources that involve very little effort and are very easy to use. For example: TV, talking with friends, and Facebook."), while P31 meticulously hunts down his news:

When I go looking for news at home I load the following pages in different tabs, Stuff.co.nz, Engadget and ESPN Soccernet. Then I'll open a few headlines from the first page in new tabs and close that news source. ... Once I've found a few good news items on the next page I'll open them in new tabs then go back to the other tabs I opened since they should have loaded now. I'll then read those news items... Then once I've finished the news items from the first source, I'll move on to the ones from the second source. ... I'll end up opening heaps of tabs then slowly work my way through them.

'Media multitasking' [9], the simultaneous information consumption from multiple sources, is recognized as a common behavior. Here, news consumption is interleaved with other entertainment activities (watching non-news TV shows) as well as serious activities (such as university assignments): "I get into bed ... Then I turn my laptop on and start checking my emails, facebook, homework and I like to watch television episodes as well for background noise and something to watch. I like to flick between Facebook, NZ Herald web site and working on my homework..." [P9] Media multitasking can be deliberate (as with P9), or it can occur unintentionally ("Since I have a widget on my phone constantly updating me with news I simply 'ran across' a news item while checking a text message that caught my eye." [P1]).

While selected news items may be read or viewed carefully, students also engage in news satisficing behavior - getting the gist of a text news item by scanning news headings, summaries, or snippets, or by overhearing/viewing bits of news in passing. P12, for example, follows the New Zealand Herald newspaper and CNN on Twitter, and will 
"normally just read the headline on their tweet" rather than the entire tweet, much less follow a link to the full story. News applications that more readily support text news satisficing by prominently displaying headers and snippets are preferred to older-style interfaces that direct the reader through topic hierarchies before arriving at the news summaries; P11, for examples, resents having to "take time to read the headers and subheaders of categories to find the information you want".

Searching for news related to a specific event (in contrast to encountering news on the event from existing feeds or browsing news resources) is often in reaction to exposure to a news snippet. When the snippet is encountered from face-to-face conversations or glancing at physical media, the most common response is to search online news sources for further details (rather than, for example, purchasing the magazine or newspaper). When the snippet is encountered online, the student may simply retrieve and read the text associated with the snippet, or may search additional sites for alternative viewpoints or updates. Social media such as Facebook or Twitter are more likely to be consulted when the event is in an early stage, to find the most recent reports (“... posts on the latest earthquakes in Christchurch came up on Facebook well before the news sites had any information on them." [P12]).

The students wrestled with issues of trust in news media and the believability of particular news items. There was no consensus on a set of sources that were more trustworthy than others; for example, P6 points to newspapers as "a great source of trustworthy news", where $\mathrm{P} 3$ prefers informal "online sources" because "online sources follow-up is often possible to find the original news source and establish if a news item is actually true.". Personal news as encountered through text (via Facebook, SMS, Twitter, etc.) may not be accurate because "friends always boast or exaggerate" [P7]. It is easier to evaluate the believability of personal news delivered by "someone who is faceto-face, you can often tell with their body language and tone of voice whether or not what they are saying is true." [P11] In general, the believability of news in most topics depends on the trustworthiness of the source, with the single exception of celebrity news--a topic panned as being "not very believable but still very entertaining". [P22]

Six students raised additional issues affecting believability of a news item: bias on the part of the author or sharer of that item, 'spin' or deliberate inaccuracies in the presentation of the item, and perceived manipulation of the reader to view or share particular news items. As noted above, personal news is particularly prone to biased presentation, as the people involved in a story may also be reporting it. However, the problem of bias on social media sharing runs deeper, as the external stories 'shared' in an individual's Facebook page are part of that person's social image--and so can skew their nature and topics (“... people tend to make an effort to post articles about things they feel are likely to provide "Likes" or discussion among their friends and are wary when posting controversial content." [P19]).

News can be slanted through its presentation or its content, and this 'spin' can be difficult to uncover. For example, P19 checked five different sources for a single breaking story, to identify potential bias in the reporting of the event ("I found that most articles had the same main points however some reporters attempted to put spins on these points..."). P11 points a cruder source of bias: the presence of "imitation style 
websites that make up stories or fake events that people can often mistake for reality". It can be difficult to differentiate between 'real' and 'imitation' news sources-hence the importance of identifying trustworthy, believable news sites and feeds. However, even those trusted sites may include dubious stories; of the 11 students who identified Stuff.co.nz as a site that they frequently used, none acknowledged that, as a news aggregator, the site does not verify the press releases posted to it.

The final issue affecting believability - perceived manipulation of the reader's attention - is an ongoing issue for both social media and commercial news sites. In social media sites such as Reddit, users can attempt to attract greater attention to a news item by "provoking inflammatory responses from other readers" [P20] in the comments threads or attempting to "blackmail" [P12] users into sharing a posted image by attaching an emotionally manipulative caption to it. Commercial online news sites manipulate news choices by introducing "advertiser links, pop up boxes and a plethora of tricks and techniques that divert my attention from where I was hoping to go to where someone wants me to go." [P35]

\section{Summary}

As is typical for qualitative work, the contribution of this study is to point to future directions in research and development for systems supporting the news behavior uncovered here. Specifically, we raise the following questions:

- Given that news consumption is a significant relaxation and entertainment activity, how can we make news encounters more enjoyable? Is it possible to make them more attractive, more pleasant to engage with, more ludic in nature?

- How can we support the 'newshound' [10] in tracking down the minute details of a story without getting lost in the process? (E.g., "I can sometimes find myself attempting to find out exactly how far the rabbit hole goes, and end up exactly where I started several hours later." [P20])

- How can emerging, relevant sources be brought to the attention of users-and which existing sources will the new ones replace? Even the youngest of these students could reflect on sources that they once relied on but now rarely use.

- How may a personal Digital Library support up-to-date news encounters?

- How can we model a given user's news routines, and support those behaviors as they vary across times of day, days of the week, and the location of the user?

- As a user moves between different digital platforms (desktop/laptop, tablet, phone), how can we support a seamless news experience? Alternatively, should we tailor the news experience to the platform, given their different affordances? For example, small-screen mobiles are inherently well suited to 'news snacking', while desktops/laptops offer the screen real estate to support 'newshounds'.

- How can we model a given user's topics of interest, and how can we adapt that model to reflect change in those interests?

- What information presentation and organization designs can better support news satisficing? For example, how can we provide more informative news snippets, and how can we reduce the need for users to traverse topic hierarchies? 
- What changes in news provision can support our users in identifying bias? For example, can we provide multiple versions of a story from different sources, or highlight relationships (such as corporate ownership) between publishers and the entities referred to in the news reports?

\section{References}

1. Costera Meijer, I. \& Groot Kormelink, T. (2014). Checking, Sharing, Clicking and Linking: Changing patterns of news use between 2004 and 2014. Digital Journalism. doi:10.1080/21670811.2014.937149

2. Cunningham, S. J., \& Jones, M. (2005). Autoethnography: a tool for practice and education. In Proceedings of CHINZ 2005, 1-8. ACM.

3. Diddi, A. \& LaRose, R. (2006). Getting hooked on news: Uses and gratifications and the formation of news habits among college students in an internet environment. Journal of Broadcasting and Electronic Media, 50, 193-210.

4. Gao, T., Hullman, J. R., Adar, E., Hecht, B., \& Diakopoulos, N. (2014, April). NewsViews: an automated pipeline for creating custom geovisualizations for news. Proceedings of the Conference on Human factors in computing systems. ACM. 3005-3014.

5. Glaser, B., Strauss, A., (1967) The Discovery of Grounded Theory: Strategies for Qualitative Research, Chicago.

6. Hermida, A., Fletcher, F., Korell, D., \& Logan, D. (2012). Share, like, recommend: Decoding the social media news consumer. Journalism Studies, 13(5-6), 815-824.

7. Lee, C.S. \& Ma, L. (2012). News sharing in social media: The effect of gratifications and prior experience. Computers in Human Behavior, 28(2), 331-339.

8. Leino J., Räihä, K.J., \& Finnberg, S. ( 2011). All the news that's fit to read: finding and recommending news online. Proceedings of INTERACT'11, Springer-Verlag. 169-186.

9. McDonald, D. G., \& Meng, J. (2009). The multitasking of entertainment. In: Kleinman, S. (ed.) The culture of efficiency: Technology in everyday life. New York: Peter Lang. 142-157.

10. Culture of Efficiency: Technology in Everyday Life. Peter Lang, New York (2009)

11. Marshall, C.C. 2007. The gray lady gets a new dress: a field study of the Times News Reader. In Proceedings of JCDL '07. ACM, New York, NY, USA, 259-268.

12. Nielsen, R.K. \& Schrøder, K. C. (2014). The relative importance of social media for accessing, finding, and engaging with news: An 8-country cross-media comparison. Digital Journalism, 2(4), 472-489.

13. Pentina, I. \& Tarafdar, M. (2014). From "information" to "knowing": Exploring the role of social media in contemporary news consumption. Computers in Human Behavior, 35, 211-223.

14. Resch, A., Berk, J., \& Akers, L. (2014). Recognizing and Conducting Opportunistic Experiments in Education: A Guide for Policymakers and Researchers. REL 2014-037. National Center for Education Evaluation and Regional Assistance, USA.

15. Samet, H., Sankaranarayanan, J., Lieberman, M. D., Adelfio, M. D., Fruin, B. C., et al.. (2014). Reading news with maps by exploiting spatial synonyms. Communications of the ACM, 57(10), 64-77.

16. van Damme, K., Courtois, C., Verbrugge, K. \& Marez, L. (2015). What's APPening to news? A mixedmethod audience-centered study on mobile news consumption. Mobile Media \& Communication, 3(2), 196-213.

17. Yadamsuren, B. \& Erdelez, S. (2010). Incidental exposure to online news. Proceedings of the American Society for Information Science and Technology, 47(1) 1-8. 